\title{
Assay of Urinary Kinin
}

\author{
By \\ Kaoru Yoshinaga, Keishi Abe, Isao Miwa, \\ Mitsuyasu Aida, Masaru Maebashi and \\ Yasuo Wada \\ From the Department of Internal Medicine, \\ Tohoku University School of Medicine, \\ Sendai; Director: Prof. T. Torikai \\ (Recieved for publication, November 12, 1963)
}

\begin{abstract}
An assay method of urinary kinin was described. It consists of extraction of the peptide into $n$-butanol, re-extraction back to a weak acid solution, concentration under reduced pressure, neutralization and bioassay on the isolated guinea-pig ileum.

The method was fairly simple and can be carried out without difficulty. The recoveries and the accuracy proved satisfactory. The method is also specific for the kinin in urine.

Ten to thirty micrograms of kinin were excreted daily by healthy persons.
\end{abstract}

In 1952, Beraldo ${ }^{1)}$ found in urine of the dog an active principle which stimulated the contraction of the terminal ileum of the guinea-pig. The principle, designated as Substance $U$, was assumed to be a polypeptide, for it was dialyzable and easily destroyed by the incubation with chymotrypsin. Two years later, Werle and Erdös ${ }^{2}$ reported a similar substance in human urine under the name of Substance Z.

Recently, it has been found ${ }^{3}$ that the Substance $U$ or $Z$ cannot be distinguished from bradykinin or kallidin in its chemical and biological characteristics, and the name of urinary kinin has been given to this peptide.

The urinary kinin has been investigated by several authors ${ }^{3-7}$. In their studies the purification of the peptide was usually attained with the aid of ionexchange resin Amberlite IRC-50.

In contrast to the original reports, however, the recovery of kinin through the resin treatment was found very low in our laboratory. A reliable assay method should be newly developed in order to estimate the urinary kinin. The study presented in this paper was undertaken in an effort to establish a simple and practical method for the assay of human urinary kinin.

吉永 整, 阿部圭志, 三輪 相田光保, 前橋 賢, 和田保男 


\section{METHOD}

\section{Extraction}

Twenty ml. of urine were acidified with $2 \mathrm{~N}$ hydrochloric acid down to $\mathrm{pH}$ 1.5 (indicator paper, CR), saturated with solid sodium chloride, and extracted with equal volume of $n$-butanol under vigorous shaking for 5 minutes. After centrifugation at $3,000 \mathrm{rpm}$ for 10 minutes, the organic phase was pipetted to another centrifuge tube. The extraction was repeated once with 0.5 volumes of butanol. Both extracts were combined, and $15 \mathrm{ml}$. of petroleum ether were added. The mixture was re-extracted twice with $2 \mathrm{ml}$. of distilled water under shaking for 5 minutes.

The combined aqueous extract was transferred to a graduated glass tube. It was then concentrated under reduced pressure to a volume around $0.6 \mathrm{ml}$. Evaporation was carried out without air inlet at a temperature below $40^{\circ} \mathrm{C}$. During the concentration, the tube was shaken manually to avoid the burst-out of the internal fluid, the shaking having the advantage to facilitate the evaporation.

One drop of 0.05 per cent brom-thymol blue (BTB) was added to the concentrated extract, which was then titrated with $2 \mathrm{~N}$ sodium hydroxide till the bluish tone of BTB appeared. The neutrality of the extract was attained with small volume of $0.5 \mathrm{~N}$ hydrochloric acid and $0.1 \mathrm{~N}$ sodium hydroxide. Final volume of the extract was adjusted to $1.5 \mathrm{ml}$. with water.

The faintly yellowish extract thus prepared was ready for assay. If desired, the extract was stored in a deep-freezer until the bioassay.

\section{Bioassay}

Guinea-pigs weighing 150-300 g., both sexes, were used. The animal was killed by a blow on the head, weighed, and bled from the carotid arteries. The ileum was cut $2-3 \mathrm{~cm}$. apart from its terminal end, and freed from the mesenterium. Approximately $10 \mathrm{~cm}$. strip was cut out, washed thoroughly with warmed Tyrode through the lumen. A $2-3 \mathrm{~cm}$. portion of the anal side was used for the assay. The remaining part was stored in Tyrode at $4^{\circ} \mathrm{C}$.

The ileum strip was mounted in a $10 \mathrm{ml}$. bath filled with Tyrode at $35-37^{\circ} \mathrm{C}$. Counterbalance was $0.5-1.0 \mathrm{~g}$. After 2-3 hours' equilibration with aeration, test dose of standard bradykinin was added to the bath. Contractions of the ileum were recorded 10 fold magnified on a smoked kymograph with a lever. Standard solution containing $0.5-1.5 \mu \mathrm{g} . / \mathrm{ml}$. was prepared dissolving the synthetic bradykinin in Tyrode.

If the strip showed irregular spontaneous contractions, atropine sulfate $\left(10^{-7}-10^{-8}\right)$ was added to the perfusing fluid.

When the reactions of the strip reached constant to a given dose of the standard, the sample was assayed by the four-points method. Dose interval 
was fixed at 5 minutes.

\section{COMMENT ON THE METHOD}

\section{Stability of the Kinin}

When the urine was allowed to stand at room-temperature, its kinin content decreased rapidly as shown in Fig. 1, the half-time being approximately 4 hours. When stored at $4^{\circ} \mathrm{C}$, however, the kinin was quite stable up to 24 hours so

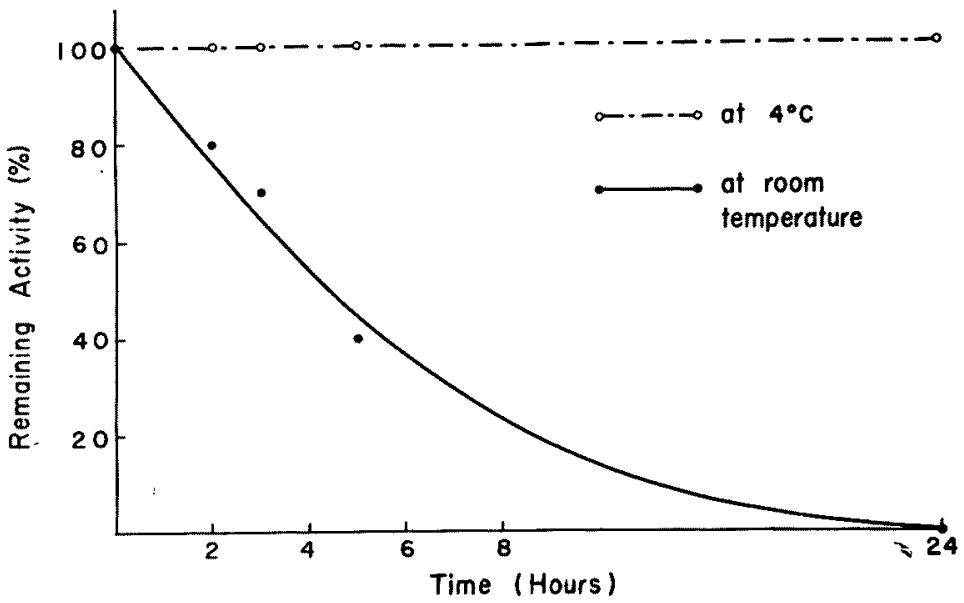

Fig. 1. Stability of kinin in urine at $4^{\circ} \mathrm{C}$ and room-temperature.

long studied. Again the urinary kinin was completely preserved as long as 4

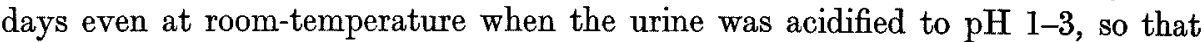
the urine could be safely left for several days before extraction if it was immediately acidified after its voidance. When the urine was stored in a deep-freezer, whether acidified or not, the kinin was infinitely stable.

The kinin in the final neutral extract, or the synthetic peptide dissolved in Tyrode was also stable at $4^{\circ} \mathrm{C}$ or $-20^{\circ} \mathrm{C}$; whereas $10-20$ per cent decrease in their activities was observed during the course of several hours at room temperature.

\section{Extraction and Recovery}

In the initial stage of this study, previously reported methods were used to extract the urinary kinin. Butanol extraction and back-extraction to the aqueous phase proved quantitative, but the column procedure or resin treatment was inadequate.

When the urine was treated with alumina column according to Horton ${ }^{\text {), }}$ the activity was not eluted in a sharp peak but scattered to a number of fractions; effective concentration of kinin and elimination of contaminating activities 
were not achieved.

When the urine was treated with ion-exchange resin Amberlite IRC-50 using the column method according to Gaddum ${ }^{3}$, or using the batch-wise method of Jensen $^{8}$, recoveries of kinin were constantly lower than 50 per cent.

Attempts were then made to extract the kinin with the strong cationic resin Dowex-50. Though the urinary kinin was completely retained by the resin, it was scarcely eluted from the resin with alkali or acid. This finding was surprising enough, because angiotensin can be easily eluted quantitatively from the resin with a small volume of $0.1 \mathrm{~N}$ sodium hydroxide ${ }^{9}$. Angiotensin was completely separated from the kinin by a simple resin-chromatography.

Urinary kinin was quantitatively recovered by the present method. The only disadvantage of this method was that the final extract contains a considerable amount of sodium chloride, the concentration being approximately $0.4 \mathrm{~N}$. But, as described below, this degree of salt content had no influence on the response of guinea-pig ileum.

\section{Specificity}

The active substance extracted as above elicited the typical "slow contraction" on the isolated guinea-pig ileum and rat uterus in the same fashion as standard bradykinin. Its activity was not blocked by atropine $\left(10^{-7}-10^{-6}\right)$ or promethazine hydrochloride, a potent antihistaminic agent $\left(10^{-9}-10^{-7}\right)$.

To characterize the urinary kinin, the extract was subjected to paper chromatography: The extract was evaporated to dryness, and the residue was taken up with a small volume of 80 per cent ethanol. The alcoholic extract was plotted linearly on Toyo Roshi No. 51 (which corresponds to Whatman No. 1), $5 \times 40 \mathrm{~cm}$., and developed for 18 hours at around $18^{\circ} \mathrm{C}$ using butanol-acetic acid-water $(4: 1: 1 \mathrm{v} / \mathrm{v})$ as the solvent. After the chromatography, the paper was dried and cut at each $1 \mathrm{~cm}$. distance along the parallel lines to the original one. Each fraction was assayed on the ileum by dipping the paper directly to the bath. As shown in Fig. 2, activity was sharply localized at Rf 0.27 , no other active fraction being observed. When the synthetic bradykinin was added to the urine extract and chromatographed in the same way, the peak at Rf 0.27 was greatly enhanced and other fractions caused no response. Thus the principle in the extract was chromatographically pure and not distinguished from the synthetic bradykinin.

To characterize the urinary kinin against proteolytic enzymes, incubation experiments were performed as formulated in Table I. The extracted kinin was completely destroyed by chymotrypsin and human serum kininase, whereas only partial inactivation was observed in the experiments with trypsin. In all the experiments the rate of inactivation was quite the same between urinary kinin and the authentic bradykinin added to the extract.

From these results, it may be safely concluded that the urinary kinin estimated 


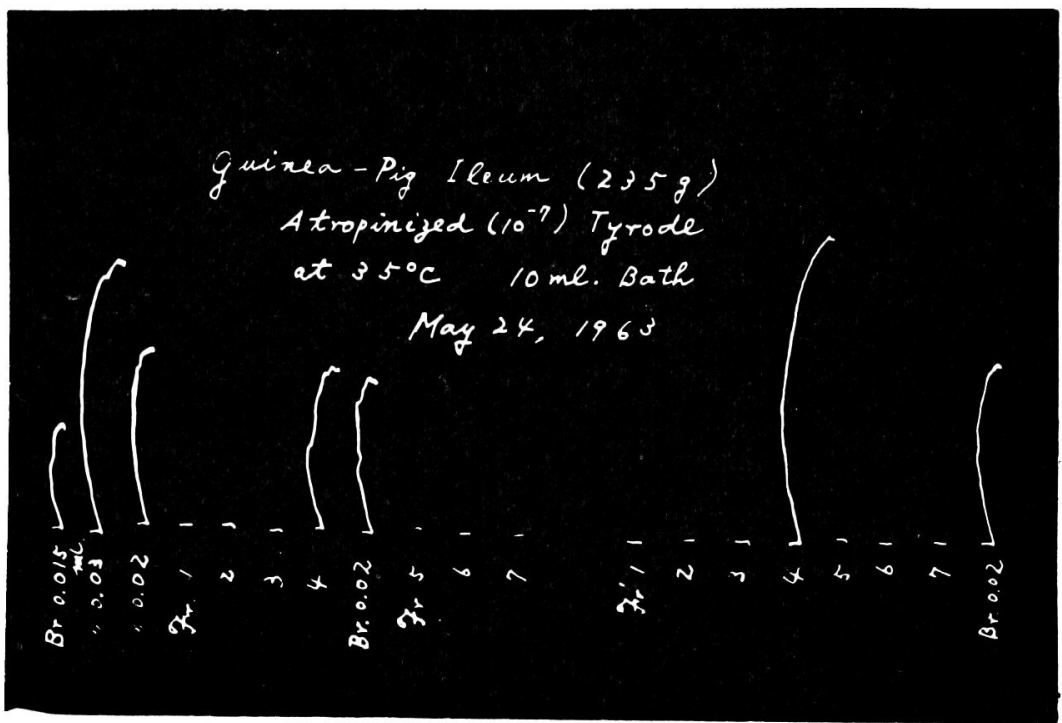

Fig. 2. Paperchromatography of urinary extract.

Br., Synthetic bradykinin $(0.25 \mu \mathrm{g} . / \mathrm{ml}$.).

Fr., Fractions of paper cut as described in text.

Fr'., Fractions of the paper to which urinary extract plus synthetic bradykinin was applied.

TABLE I. Incubation Experiment. Samples Were Incubated for $1 \mathrm{Hour}$ at $37^{\circ} \mathrm{C}$ at $\mathrm{pH}$ 7.4, and Heated in Boiling Water Bath for 5 Minutes

\begin{tabular}{l|c|c|c|c}
\hline & Blank & $\begin{array}{c}\text { Chymotrypsin } \\
\text { (lmg./ml.) }\end{array}$ & $\begin{array}{c}\text { Trypsin } \\
\text { (lmg./ml.) }\end{array}$ & Serum \\
\hline Urinary cxtract(ml.) & 1.0 & 1.0 & 1.0 & 1.0 \\
Enzyme solution(ml.) & - & 0.1 & 0.1 & 0.1 \\
Remaining activity(\%) & 100 & 0 & $100-50$ & 0
\end{tabular}

by the present method is identical with the nonapeptide bradykinin. But the identification has not been finally settled, because there remains the possibility that the decapeptide kallidin might not have been differentiated from the bradykinin in the procedures described above. In this study, the presence or absence of kallidin could not be investigated because of its lack in our laboratory.

\section{Bioassay}

The assay of kinin has been generally carried out on the isolated rat uterus or guinea-pig ileum, the former being more sensitive than the latter.

In our laboratory, however, the rat uterus was found very unstable in its responses to the kinin, and it showed quite often spontaneous contractions which could not be suppressed by atropine or antihistaminics. These disadvantages 
were not overcome by changing the concentrations of calcium in de Jalon's solution, or by changing the temperature of the perfusing fluid. The use of this organ was finally abandoned though the preparation had a very high sensitivity to the kinin.

The guinea-pig ileum was quite satisfactory for the assay. But it sometimes contracted spontaneously. Atropine sulfate $\left(10^{-7}-10^{-6}\right)$ usually made the strip quiescent. Immediately after bathing, the ileum was refractory to the kinin stimulus, the contractility restoring fully after $2-3$ hours' equilibration.

When the ileum was stored for $12-24$ hours in Tyrode at $4^{\circ} \mathrm{C}$, it was more sensitive and spontaneous contractions were less frequent than the fresh one.

Since the extract contained approximately $0.4 \mathrm{~N}$ sodium chloride, the effect of saline in various concentrations was tested on the ileum. When $0.5 \mathrm{ml}$. of saline solution was added to the $10 \mathrm{ml}$ bath, small contractions were elicited by $0.6 \mathrm{~N}$ solution; the higher the concentrations of the salt, the greater the responses. But no response was observed by the saline concentrations lower than $0.6 \mathrm{~N}$. Since the extract was added to the bath in doses ranging $0.05-0.5 \mathrm{ml}$., the salt might have had no influence on the ileum.

The sensitivity of the strip to the kinin was surprisingly variable from ileum to ileum, the threshold ranging 1-15 $\mathrm{ng}$. per $\mathrm{ml}$. of the bath fluid. It was a general rule that the sensitivity decreased progressively with the body weight of the guinea-pig.

To test the accuracy of the method, known amounts of standard bradykinin were assayed without the knowledge of its concentrations. The results were fairly good as shown in Table II. Errors around \pm 10 per cent were inevitable.

TABLE II. Assay of Known Bradykinin Solution

\begin{tabular}{c|c|c|c}
\hline No. of Exp. & Content $(\mu \mathrm{g})$. & Assayed $(\mu \mathrm{g})$. & Error $(\%)$ \\
\hline 1 & 3.00 & 2.73 & -9.0 \\
2 & 2.25 & 2.50 & +11.1 \\
3 & 1.50 & 1.67 & +8.0 \\
4 & 1.50 & 1.50 & 0.0 \\
5 & 1.50 & 1.80 & +20.0 \\
6 & 0.75 & 0.75 & 0.0 \\
7 & 0.75 & 0.62 & -17.9
\end{tabular}

Standard deviation $(\%) . \pm 12.5$

\section{Excretion of Urinary Kinin}

Urines from healthy persons were collected in bottles containing $10 \mathrm{ml}$. of conc. hydrochloric acid. An aliquot of $20 \mathrm{ml}$. from each specimen was extracted and assayed. The results are listed in Table III. The values ranged $10-30 \mu \mathrm{g}$. per daily urine, and were in good accordance with those reported by Horton ${ }^{10}$. 
K. Yoshinaga et al.

TABLE III. Excretion of Urinary Kinin in Healthy Persons

\begin{tabular}{l|c|c|c}
\hline Subjects & Age & Sex & $\begin{array}{c}\text { Urinary kinin } \\
(\mu \mathrm{g} . / 24 \text { hours })\end{array}$ \\
\hline M. L. & 51 & $\wp$ & 10.0 \\
A. F. & 39 & $\wp$ & 22.0 \\
K. K. & 51 & $\delta$ & 14.7 \\
M. H. & 57 & $\delta$ & 17.0 \\
K. S. & 15 & $\delta$ & 15.0 \\
K. Y. & 34 & $\delta$ & 25.7 \\
T. M. & 43 & $\wp$ & 10.8 \\
I. M. & 31 & $\delta$ & 31.4 \\
H. S. & 45 & $\wp$ & 18.9 \\
K. A. & 30 & $\delta$ & 33.8 \\
& & &
\end{tabular}

\section{DISCUSSION}

Remarkable progress has recently been made in the field of biologically active kinins, kallidin and bradykinin. Their chemical structures were determined as deca- and nona-peptide respectively ${ }^{11,12}$, and the both kinins are now available in synthetized pure form. Symposia have been repeatedly held on the theme of the kinins. It has been postulated that the peptides play many important roles in the pathogenesis of shock, allergic diseases, or in the process of the inflammation. But their pathophysiological significance in diseased conditions has been completely unknown, because they have never been investigated on the clinical standpoint. The first step demanded for the clinical studies was the development of a reliable method for the estimation of the kinin.

The method presented in this paper for the determination of urinary kinin is fairly simple, accurate and specific; so that it may be useful in the clinical studies on the peptides. Estimations of the kinin over many patients are now under progress.

The origin of urinary kinin has been unknown. It has been confirmed ${ }^{13}$ that the physiological hyperemia in the salivary gland or sweat gland during their activities is caused by plasma kinin liberated locally. Horton ${ }^{7}$ reported, however, that there was no increase in urinary kinin during sweating or salivation. Whether the kinin in systemic circulation is excreted through the kidney into urine or the kidney itself produces and secretes the urinary kinin has not been clarified. The problem of the source of urinary kinin awaits future investigation.

\section{Acknowledgment}

We are greatly indebted to Dr. A. Fanchamps and Dr. W. v. Orelli for giving us the synthetized peptide bradykinin, and to Prof. T. Torikai and Prof. K. Hashimoto, Department of Pharmacology, Tohoku University School of Medicine, for their leadership throughout this study. 


\section{References}

1) Beraldo, W.T., Amer. J. Physiol., 1952, 171, 371.

2) Werle, E. \& Erdös, E.G., Arch. Exper. Path \& Pharmak., 1954, 223, 234.

3) Gaddum, J.H. \& Horton, E.W., Brit. J. Pharmacol., 1959, 14, 117.

4) Gomes, F.P., Brit. J. Pharmacol, 1955, 10, 200.

5) Walaszek, E.G., Brit. J. Pharmacol., 1957, 12, 223.

6) Jensen, K.B., Brit. J. Pharmacol., 1958, 13, 271.

7) Horton, E.W., Brit. J. Pharmacol., 1959, 14, 125.

8) Jensen, K.B. \& Vennerod, A.M., Acta Pharmacol., (Kbh.) 1962, 19, 265.

9) Yoshinaga, K., Aida, M., Maebashi, M., Sato, T., Abe, K. \& Miwa, I., Tohoku J. Exper. Med., 1963, 80, 32.

10) Horton, E.W., Polypeptides Which Affect Smooth Muscles and Blood Vessels, Schachter M., Pergamon Press, New York, 1960.

11) Elliott, D.F. Lewis G.P. \& Horton, E.W., Biochem. Biophys. Res. Commun., 1960, 3, 87.

12) Pierce, J.V. \& Webster, M.E., Biochem. Biophys. Res. Commun., 1961, 5, 353.

13) Hilton, S.M. \& Lewis, G.P., J. Physiol., 1956, 134, 471. 